\title{
Numerical simulation of a water infiltration test on a proposed backfill mate- rial in nuclear waste repositories
}

\author{
Abhishek Rawat ${ }^{1, *}$, Anne Catherine Dieudonne ${ }^{2}$, Wiebke Baille ${ }^{1}$, and Frederic Collin ${ }^{3}$ \\ ${ }^{1}$ Ruhr-Universität Bochum, Chair of Foundation Engineering, Soil and Rock Mechanics, Universitätstr. 150, 44780 Bochum, Germany \\ ${ }^{2}$ Delft University of Technology, the Netherlands, Building 23, Stevinweg 12628 CN Delft, The Netherland \\ ${ }^{3}$ ArGEnCo, University of Liege, Quartier Polytech 1, Allee de la decouverte 9 - Batiment B52 4000 Liege, Belgium
}

\begin{abstract}
A water infiltration test was numerically simulated using the finite element method. The modified Barcelona Basic Model and the double-structure water retention model was used for the numerical analysis. A methodology is presented for parameter identification and calibration purpose. The experimental results highlighted the porosity redistribution and hydration-induced heterogeneity along the hydration-path. The simulation results successfully captured the moisture migration in the soil sample. A comparison between the measured and predicted total stress values revealed the influence of interfacial friction between the soil sample and cell wall.
\end{abstract}

\section{Introduction}

The Barcelona Basic Model (BBM) proposed by Alonso et al. [1] is one of the most popular elastoplastic models and suitable for predicting the mechanical behaviour of collapsible soils and low to moderate expansive soils. Several modifications have been suggested in the original formulation of the BBM $[2,3]$ to reproduce the swelling potential of compacted bentonite-based materials. For the modeling of coupled flow and deformation problems, the indirect coupling is introduced by incorporating the soilwater retention model. Recently, Dieudonne et al. [4] proposed a model, which considers different water retention mechanisms in each structural levels of a compacted bentonite, namely adsorption in the intra-aggregate pores and capillarity in the inter-aggregate pores. One of the major challenges in the simulation of coupled hydro-mechanical problems are the large number of model parameters, as a result, the model calibration and the parameter identification is not straightforward $[5,6]$.

In this regard, a small-scale water infiltration test was conducted to mimic the transient hydration of a proposed backfill material in repositories. The effect of groundwater geochemistry is not considered in this study. In the numerical analysis, the water infiltration test was simulated using the Finite Element code LAGAMINE. The modified BBM along with the recently developed double-structure water retention model [4] were used. The test results highlighted the key features of hydration-induced processes in unsaturated compacted expansive soils.
Table 1. Geotechnical properties of soil tested

\begin{tabular}{lr}
\hline Property & Value \\
\hline Specific gravity (-) & 2.725 \\
Liquid limit (\%) & 60 \\
Plastic limit (\%) & 32 \\
Plasticity index (-) & 28 \\
\hline
\end{tabular}

\section{Material}

The investigated material was the compacted mixture of Calcigel bentonite and sand having an equal dry mass ratio. Calcigel is a commercially available bentonite from the southern part of Germany with $60-70 \%$ montmorillonite. Table 1 summarizes the relevant geotechnical properties of the tested materials. The Calcigel powder has $6 \%$ hygroscopic moisture content. For preparing the moist mixture, the distilled water was added to the ovendried medium sand [7]. The moist-mixture was stored in a sealed plastic bag and kept in an airtight container for homogeneous moisture distribution for a period of 28 days.

\section{Methods}

\subsection{A Column-type test device}

A column-type experimental device is designed for investigating the coupled hydro-mechanical behaviour of soil under an applied hydraulic gradient. The technical details of the experimental device can be found in Rawat et al. [8]. The device facilitates the transient measurements of axial swelling pressure, lateral swelling pressure, and the simultaneous measurements of temperature, water content and relative humidity along the height of cylindrical soil

*e-mail: abhishrawat@gmail.com 
specimen $($ dia. $=150 \mathrm{~mm}$; height $=300 \mathrm{~mm})$, these sensors were installed at three measurement sections i.e. X1 at $50 \mathrm{~mm}, \mathrm{X} 2$ at $150 \mathrm{~mm}$, and $\mathrm{X} 3$ at $250 \mathrm{~mm}$ from the bottom face.

\subsection{Sample preparation}

The mixture of Calcigel bentonite and sand with $9 \%$ initial water content was compacted in three layers using uniaxial static compaction under $30 \mathrm{MPa}$ vertical stress to achieve the targeted initial dry density of 1.80-1.85 $\mathrm{Mg} / \mathrm{m}^{3}$. During the compaction process, the surface of compacted layer was scarified prior to place the next layer to ensure a proper homogeneous connection between two consecutive layers. The initial suction i.e., 26.9 MPa was measured with the chilled mirror dew-point technique. After the compaction, the compacted block was extruded from the mould, the achieved mean dry density was 1.85 $\mathrm{Mg} / \mathrm{m}^{3}$ (block dia. $=153 \mathrm{~mm}$; height $=100 \mathrm{~mm}$ ). Total three blocks were compacted to achieve the required overall height of $300 \mathrm{~mm}$ inside the experimental device, these blocks exhibited post-compaction residual lateral strains during the extrusion from compaction mould. A detailed description of the installation procedure of various monitoring sensors can be found in Rawat et al. [8].

\subsection{Water infiltration test}

The test was conducted under a constant volume condition at room temperature; the air outlet at the bottom plug was kept closed, while the air outlet at top plug was kept open to evacuate the pore-air during the hydration process. In this study, the effect of groundwater geochemistry on the clay-water interaction is not considered. The distilled water was supplied from the bottom-end under $15 \mathrm{kPa}$ hydration pressure to mimic the water ingress from the host rock. Sensors along with data logger continuously monitored temperature, relative humidity, water content and total stress in both axial and lateral directions. The test was conducted for a period of 349 days. For the post-experimental measurements, the soil samples were collected from different locations along the height during the dismantling of test set-up. The relative humidity was measured using the chilled mirror dew-point technique, whereas the water content was measured using the ovendrying method.

\subsection{Numerical simulation}

A fully coupled hydro-mechanical analysis of the water infiltration test was performed using the Finite Element code LAGAMINE. The modified Barcelona Basic Model (BBM) [1] along with the soil water retention model proposed by Dieudonne et al. [4] were used for this purpose. For the simulation, a 2D axisymmetric model along Y-axis is selected for a fully coupled hydro-mechanical analysis. The model dimensions were selected according to the sample size in the water infiltration test (dimension along $\mathrm{X}$ axis $=75 \mathrm{~mm}$; dimension along Y-axis $=300 \mathrm{~mm}$ ). The initial stress in the material was assumed to be atmospheric (isotropic), which was equal to $0.1 \mathrm{MPa}$. An isoparametric quadrilateral element (2D) with 8 nodes was selected for the analysis. The element for $2 \mathrm{D}$ case posses five degrees of freedom at each node: two displacements of the soil skeleton in $\mathrm{X}$ and Y-direction, a liquid water pressure, a gas (dry air+vapor) pressure and temperature. The temperature in this study was kept constant at $20{ }^{\circ} \mathrm{C}$. The initial total suction of the material was assigned to 26.90 $\mathrm{MPa}$. For initiating the hydration, the liquid pressure at the bottom nodes were changed accordingly to a hydrationpressure of $15 \mathrm{kPa}$.

\section{Identification and calibration of model parameters}

The parameter selection is one of the major challenges in the coupled hydro-mechanical analysis due the lack of standard procedures for calibrating the constitutive models for unsaturated soils. In this respect, a detailed and systematic procedure is presented for identifying and calibrating the model parameters for the compacted bentonitesand mixture from the conventional laboratory tests.

\subsection{Parameters for mechanical behaviour}

In this study, a total of four suction-controlled oedometer tests were performed on the compacted samples of bentonite-sand mixture (50:50). The high pressure oedometer device was used, which facilitated the suctioncontrolled oedometer tests at higher vertical stress levels (up to $40 \mathrm{MPa}$ ). The soil samples (dia. $=50 \mathrm{~mm}$; height $=$ $15 \mathrm{~mm}$ ) were prepared directly inside the oedometer ring using uniaxial static compaction method. The sample initial conditions (i.e., dry density $=1.80 \mathrm{Mg} / \mathrm{m}^{3}$; water content $=9 \%$ ) were similar to the compacted blocks, which were used in the water infiltration test.

The oedometer tests were performed in two stages i.e., the suction-equilibrium stage and the one-dimensional compression-rebound stage as depicted in Fig. 1. Prior to initiate the suction-equilibrium stage, the as-compacted samples were subjected to $50 \mathrm{kPa}$ surcharge pressure. Later, the vapor equilibrium technique was used to impose the desired suction-level (i.e., 3.39 or $10 \mathrm{MPa}$ ) using the saturated salt solutions. During the suctionequilibrium stage, the vertical deformation of the samples were continuously monitored. Once the sample attained the desired suction-level, the second stage i.e., onedimensional compression-rebound was initiated. For the stress-deformation characteristics of the saturated sample, the distilled water was supplied from the bottom-end under $50 \mathrm{kPa}$ surcharge load prior to initiate the loadingunloading stage. For the test with as-compacted state, the sample was directly subjected to the one-dimensional compression-rebound stage.

For testing the saturated soil sample, the swelling was allowed in the axial direction during the saturation process under $50 \mathrm{kPa}$ surcharge pressure. As the swelling was not prevented, the height of the sample increased during the saturation process. In the original formulation, 


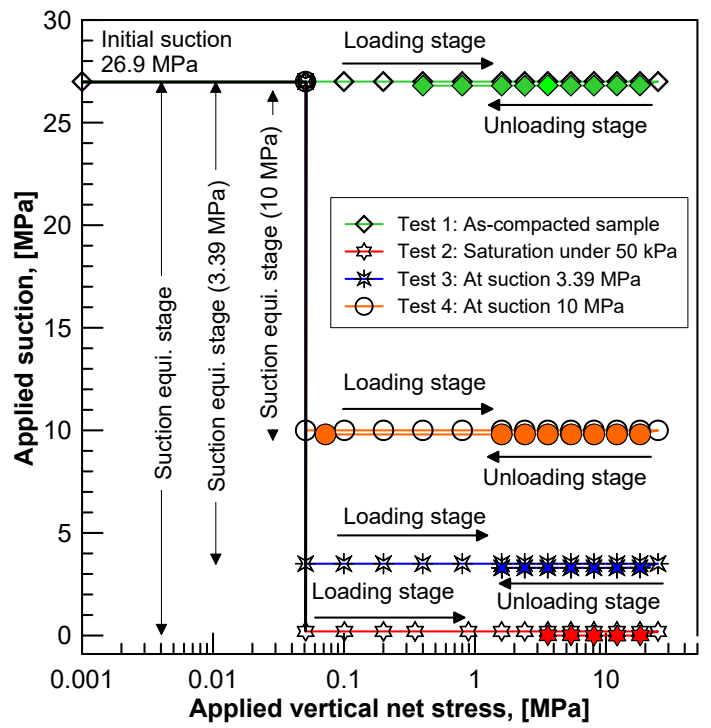

Figure 1. Stress paths for suction-controlled oedometer tests

Table 2. Barcelona Basic Model parameters (Note: P refers here parameter)

\begin{tabular}{lll}
\hline Parameter & Description & Value \\
\hline$\phi_{0}(-)$ & Initial porosity & 0.34 \\
$\psi_{0}(\mathrm{MPa})$ & Initial suction & 26.9 \\
$\lambda(0)$ & $\begin{array}{l}\text { Slope of normal compression } \\
\text { line in saturated state }\end{array}$ & 0.082 \\
& $\begin{array}{l}\text { Preconsolidation pressure in } \\
p_{0}^{*}(\mathrm{MPa})\end{array}$ & 0.6 \\
& saturated condition & \\
$p^{c}(\mathrm{MPa})$ & Relative reference pressure & $3.6 \mathrm{E} 3$ \\
$\mathrm{r}(-)$ & $\begin{array}{l}\text { First parameter defining the } \\
\text { change in } \lambda(0) \text { with suction }\end{array}$ & 1.491 \\
$\omega\left(\mathrm{MPa}{ }^{-1}\right)$ & $\begin{array}{l}\text { Second parameter defining the } \\
\text { change in } \lambda(0) \text { with suction }\end{array}$ & 0.10 \\
$k_{0}(-)$ & Initial elastic slope & 0.022 \\
$\alpha_{1}\left(\mathrm{MPa}{ }^{-1}\right)$ & P 1 related to elastic parameter & 0.011 \\
$\alpha_{2}(-)$ & P 2 related to elastic parameter & -0.215 \\
$G(\mathrm{MPa})$ & Shear modulus (for non-linear & 23.5 \\
& elasticity) & \\
$k_{s}(-)$ & Elastic slope & 0.015 \\
\hline
\end{tabular}

Alonso et al. [1] assumed that the slope of normal compression line would decrease with increasing the soil suction based on the experimental results from Josa [9] on compacted low plastic kaolin and Maswoswe [10] on compacted sandy clay. On the other hand, the oedometer tests conducted by Wheeler and Sivakumar [11] on the compacted speswhite kaolin observed the opposite behaviour as observed in the present case. To overcome this situation, where the collapse potential decreases with increasing net stress, Wheeler et al. [5] proposed a procedure for selecting a suitable values for the model parameters $r$ and $p_{c}$. The selected BBM parameters were validated against the suction-controlled oedometer tests. Table 2 summarizes the BBM parameters for compacted Calcigel bentonitesand mixture (50:50).

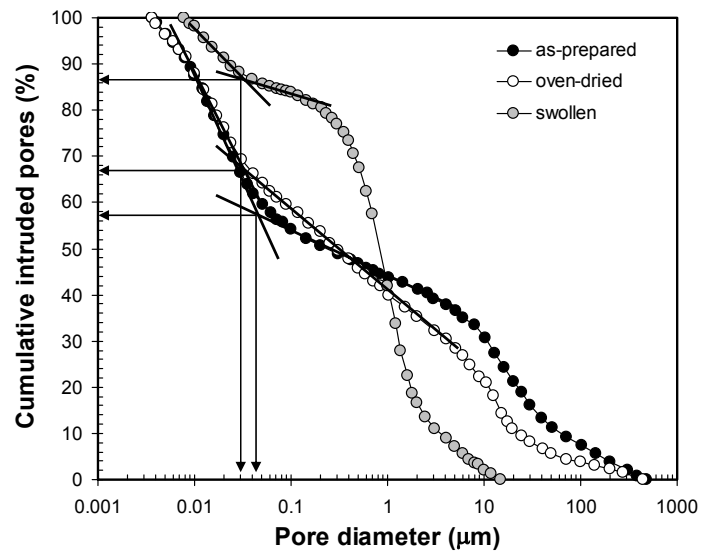

Figure 2. Determination of micro- and macropores from the pore-size distribution data from Agus [12]

\subsection{Parameters for soil-water retention behaviour}

The detailed description of model parameters and procedure for identification and calibration can be found in Dieudonne et al. [4]. The model parameters $\left(e_{m 0}, \beta_{0}\right.$ and $\beta_{1}$ ), which characterize the evolution of micro-structural void ratio with water ratio $\left(e_{w}\right)$ should be estimated first, independently from the other parameters. It requires the pore size distribution (PSD) data of the compacted mixture of Calcigel bentonite-sand (50:50) at different water ratios. Additionally, the identification of $e_{m 0}$ requires the pore-size distribution of the oven-dried sample i.e., water void ratio $e_{w}=0$. Agus [12] obtained the PSD data from MIP tests on the sample having an identical water ratio (i.e., $e_{w}=0.245$ ). The MIP tests were conducted for the as-compacted, oven-dried and swollen sample. For the preparation of swollen samples, the as-compacted sample was allowed to swell in the axial direction only. To quantify the micro-and macro-structural void ratios from the pore size distribution data, the delimiting pore sizes were identified by drawing tangents on the cumulative intrusion curves for as-compacted $(0.05 \mu \mathrm{m})$, swollen $(0.02 \mu \mathrm{m})$ and oven-dried $(0.02 \mu \mathrm{m})$ samples as shown in Fig. 2.

The MIP test data for the as-compacted sample revealed that the intra-aggregate or micro-pore volume was $59 \%$, while the inter-aggregate pore volume was $41 \%$ of the total pore volume. For the oven-dried sample, the intra-aggregate pore volume was $55 \%$, while the interaggregate pore volume was $45 \%$ of the total pore volume. For the swollen sample, the intra-aggregate pore volume was $57 \%$, while the inter-aggregate pore volume was 43 $\%$ of the total pore volume. Based on the above MIP test data the corresponding micro-and macro-void ratio were obtained for as-compacted samples $\left(e_{m}=0.30, e_{M}=0.21\right.$ for $\left.e_{w}=0.245\right)$, for oven-dried sample $\left(e_{m 0}=0.25\right.$, $e_{M}=0.20$ for $\left.e_{w}=0\right)$ and for swollen sample $\left(e_{m 0}=0.45\right.$, $e_{M}=0.35$ for $\left.e_{w}=0.80\right)$. Fig. 3 shows the evolution of microstructural void ratio with the water ratio, the obtained data were fitted with the model proposed by Della Vecchia et al. [13]. 


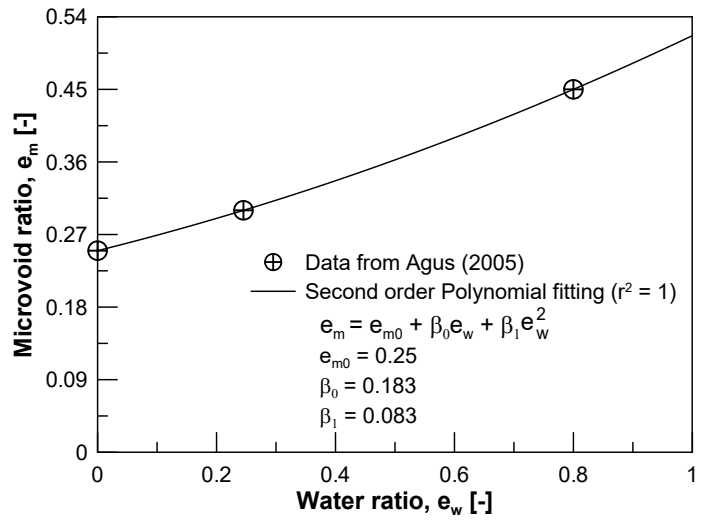

Figure 3. Evolution of micro-void ratio with water void ratio from Agus [12]

The micro-structural parameters $C_{a d s}$ and $n_{a d s}$ control the water retention behaviour at high values of soil suction. The identification of these parameters requires water retention data for as-compacted samples having different initial dry densities following the wetting path under constant volume condition. In this regard, the as-compacted sample (initial dry density $=1.8 \mathrm{Mg} / \mathrm{m}^{3}$ ) was subjected to wetting under constant volume conditions, while the experimental data for sample having $2.0 \mathrm{Mg} / \mathrm{m}^{3}$ were collected from Agus [12]. The calibration of these parameters was performed by presenting experimental data in the $\left(s-e_{w}\right)$ plane, where the independence on dry density is highlighted. A collection of points in this plane is sufficient for the calibration purpose. In particular, the parameter $C_{a d s}$ controls the slope of the water retention curve in the high suction range: the higher $C_{a d s}$, the steeper the slope of the water retention curve in the $\left(s-e_{w}\right)$ plane. Finally, the value of $e_{m}$ required to evaluate $e_{w m}$ for a given water content can be obtained using the calibrated parameters (i.e., $e_{m 0}, \beta_{0}$ and $\beta_{1}$ ).

To calibrate the macro-structural water retention model, experimental data for different initial dry densities (i.e., 1.8 and $2.0 \mathrm{Mg} / \mathrm{m}^{3}$ ) were used. The macroscopic parameter $(A)$ allows for tracking the dependency of the airentry suction on the void ratio: it can reproduce the correct evolution of the air-entry (or air-occlusion) value with the sample dry density. The parameters $n$ and $m$ control the drying-wetting rate of the material in the low suction range. Fig. 4 shows the calibration of Dieudonne water retention model and the van Genuchten model against the experimental data.

\subsection{Parameters for hydraulic behaviour}

The parameter identification for Kozeny-Carman [14, 15] formulation (Eq. 1) requires the intrinsic permeability values of saturated soil samples having different initial porosity.

$$
K=K_{0} \frac{\left(1-\phi_{0}\right)^{m}}{\phi_{0}^{n}} \frac{\phi^{n}}{(1-\phi)^{m}}
$$

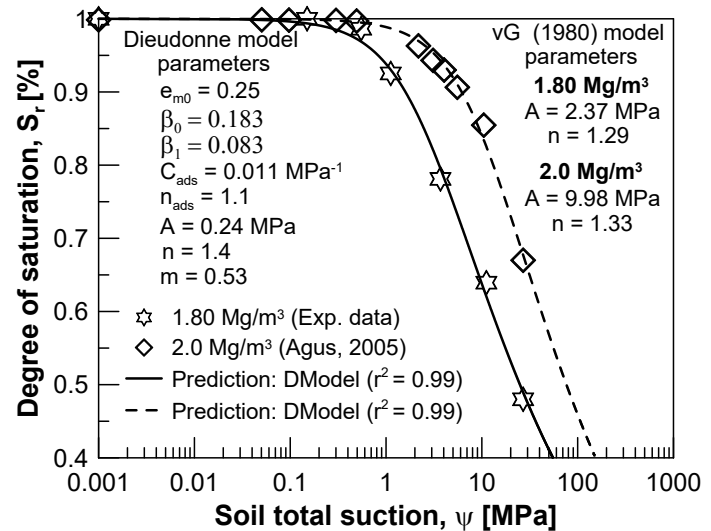

Figure 4. Calibration of soil-water retention model against the experimental data for compacted soil specimens (wetting path under confined condition).

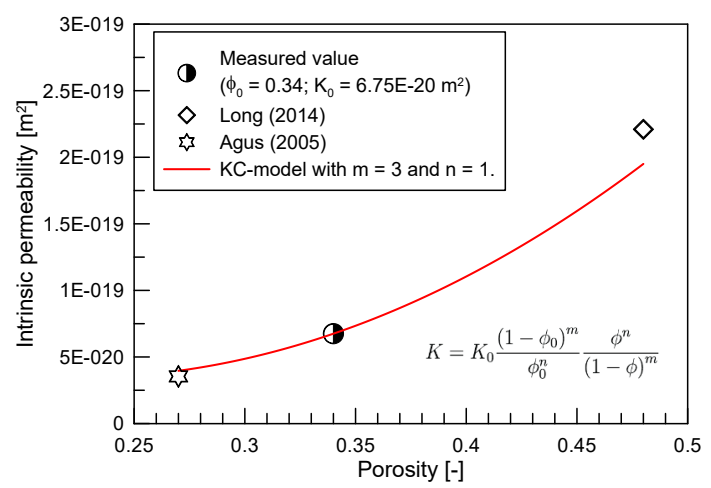

Figure 5. Calibration of parameters for Kozeny-Carman formulation

where, $K$ is intrinsic permeability $\left(\mathrm{m}^{2}\right)$ of material with porosity $\phi, K_{0}$ is intrinsic permeability $\left(\mathrm{m}^{2}\right)$ of material with reference porosity $\phi_{0}, m$ and $n$ are fitting parameter.

The saturated hydraulic conductivity values at different initial dry densities of the Calcigel bentonite-sand mixture (50:50) were collected from the literature $[12,16]$. For an initial dry density of $1.80 \mathrm{Mg} / \mathrm{m}^{3}$, the saturated hydraulic conductivity of the compacted mixture was determined from the oedometer test. The collected and measured saturated permeability data with the Kozeny-Carman model parameters for the investigated material are shown in Fig. 5. For the relative permeability in unsaturated state, a closed-form equation proposed by van Genuchten [17] was used. The parameter $\lambda$ was calibrated by best fitting the response of three relative humidity sensors located at $50 \mathrm{~mm}$ (at X1), $150 \mathrm{~mm}$ (at X2) and $250 \mathrm{~mm}$ (at X3) from the bottom-end. Table 3 summarizes the water retention parameters and the hydraulic parameters for the numerical analysis.

\section{Results and discussion}

Fig. 6 shows the comparison between predicted and measured relative humidity values over the elapsed time along 
Table 3. Hydraulic parameters for compacted bentonite-sand mixture (50:50) (Note: P refers here parameter)

\begin{tabular}{|c|c|c|}
\hline Parameter & Description & Value \\
\hline$e_{m 0}(-)$ & Micro void ratio at $e_{w}=0$ & 0.25 \\
\hline$\beta_{0}(-)$ & P 1 for micro. evolution & 0.183 \\
\hline$\beta_{1}(-)$ & P 2 for micro. evolution & 0.083 \\
\hline$C_{a d s}(\mathrm{MPa})^{-1}$ & $\begin{array}{l}\text { P } 1 \text { for adsorption (Micro- } \\
\text { level) }\end{array}$ & $\begin{array}{l}11.0 \mathrm{E}- \\
3\end{array}$ \\
\hline$n_{a d s}(-)$ & $\begin{array}{l}\text { P } 2 \text { for adsorption (Micro- } \\
\text { level) }\end{array}$ & 1.1 \\
\hline$\alpha(\mathrm{MPa})$ & A (Macro-level parameter) & 0.24 \\
\hline $\mathrm{m}(-)$ & $\begin{array}{l}\text { Shape parameter } 1 \text { for reten- } \\
\text { tion curve }\end{array}$ & 0.53 \\
\hline n (-) & $\begin{array}{l}\text { Shape parameter } 2 \text { for reten- } \\
\text { tion curve }\end{array}$ & 1.4 \\
\hline$K_{0}\left(\mathrm{~m}^{2}\right)$ & $\begin{array}{l}\text { Intrinsic permeability with } \\
\text { matrix } \phi_{0} \text { or } e_{M 0}\end{array}$ & $\begin{array}{l}6.75 \mathrm{E}- \\
20\end{array}$ \\
\hline $\mathrm{K}\left(\mathrm{m}^{2}\right)$ & $\begin{array}{l}\text { Intrinsic permeability with } \\
\text { matrix } \phi \text { or } e_{M}\end{array}$ & - \\
\hline m (-) & $\mathrm{P} 1$ for $\mathrm{KC}$ formulation & 3 \\
\hline $\mathrm{n}(-)$ & $\mathrm{P} 2$ for $\mathrm{KC}$ formulation & 1 \\
\hline$\lambda(-)$ & $\begin{array}{l}\text { Parameter for water/air rela- } \\
\text { tive permeability }\end{array}$ & 0.5 \\
\hline
\end{tabular}

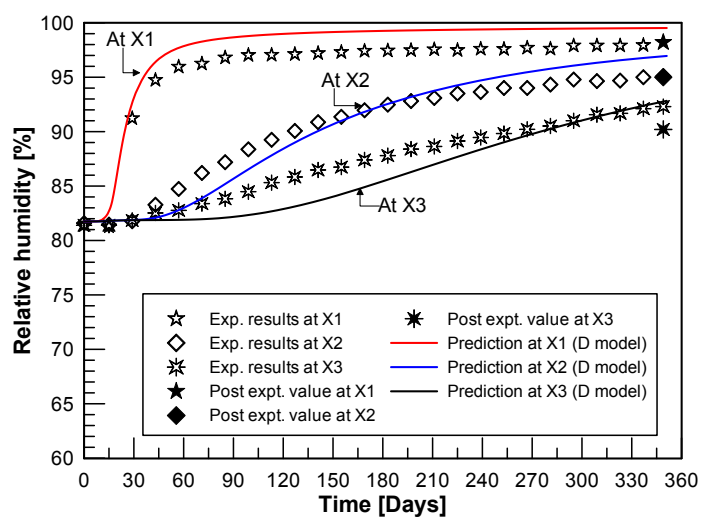

Figure 6. Elapsed time vs. relative humidity

the height of soil sample. The predicted values show a good agreement with the measured experimental values.

Fig. 7 shows the comparison between the predicted and measured water content over the elapsed time for measurement sections $\mathrm{X} 1, \mathrm{X} 2$ and $\mathrm{X} 3$. Similar to the relative humidity evolution, the effect of distance on the saturation rate is evident. Likewise, the relative humidity evolution at section $\mathrm{X} 1$, the water content increases rapidly with the initiation of hydration. The predicted values at section $\mathrm{X} 1$ agree well with the experimental results. However, the predicted values of water content were slightly higher than the measured ones.

Fig. 8 presents a comparison between the predicted and measured axial total stress at the top and bottom ends. The top load cell measured the applied stress from the bottom elements during the transient hydration process. Under a confined condition and at equilibrium, it may be anticipated that the measured axial stress at both ends of the

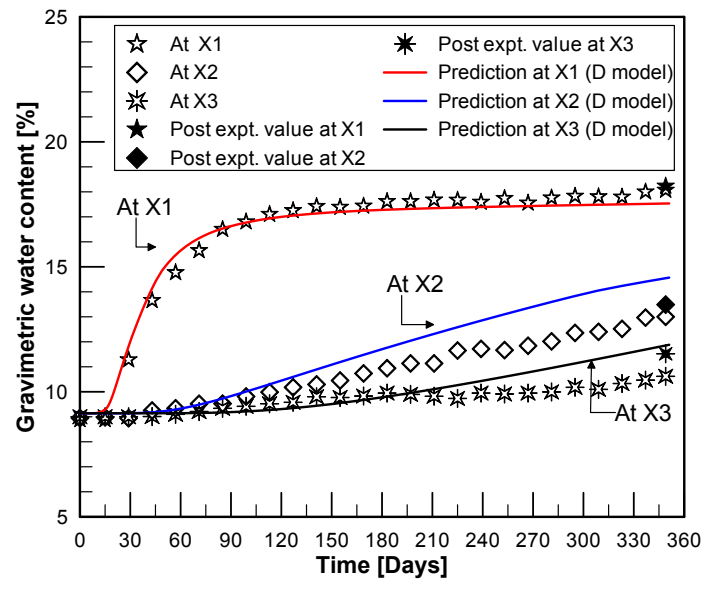

Figure 7. Elapsed time vs. water content

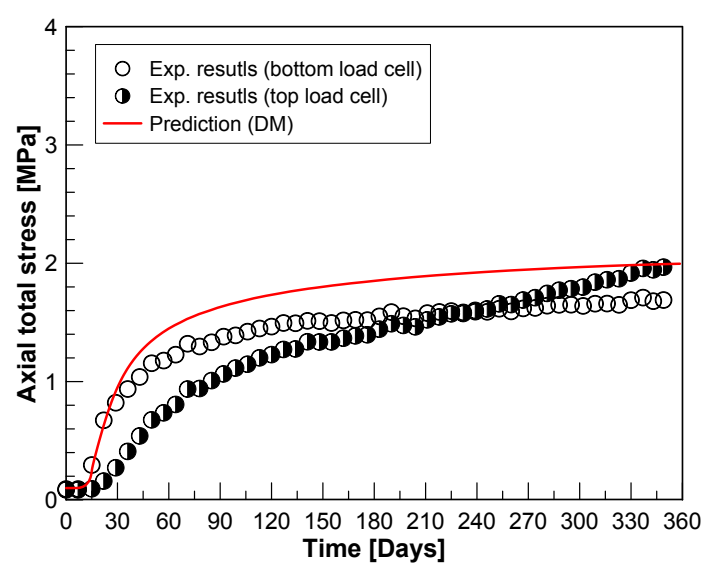

Figure 8. Measured and predicted axial stress values

sample are equal. On the other hand, it was observed during the test that the measured axial stress at both ends were dissimilar. This can be attributed to the following factors, such as (i) dissimilar compressibility characteristics along the height of the sample due to the difference in the water content along the height, (ii) the presence of construction joints meant for installing the pressure transducers, (iii) the side frictional resistance between the sample and the PVDF rings, and (iv) the composite nature of the sample due to the presence of sensors that created complex stressdeformation characteristics of the system. These features were not considered during the simulation explicitly. A decent agreement can be observed between the predicted and measured axial total stress data at the bottom-end, however the predicted values were slightly higher than the measured ones.

Fig. 9 presents a comparison between the predicted and measured values of lateral total stress along the height of soil sample. With the initiation of hydration from the bottom-end, the measured total stress at the section X1 increased quickly and reached to $2.18 \mathrm{MPa}$ within 45 days. With the further hydration, the measured values at the section X1 showed some oscillations before reaching to a value of $2.13 \mathrm{MPa}$ within 349 days. The model predic- 


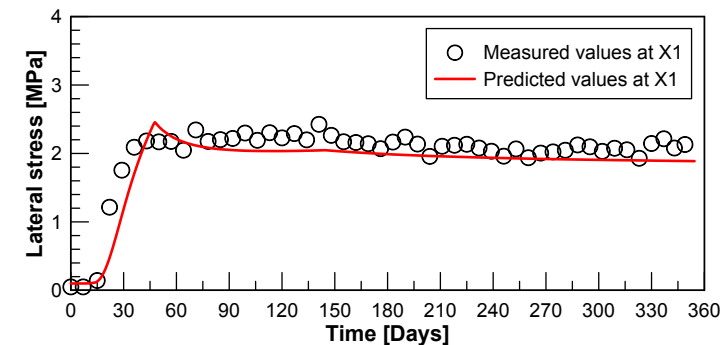

(a) At section $\mathrm{X} 1$

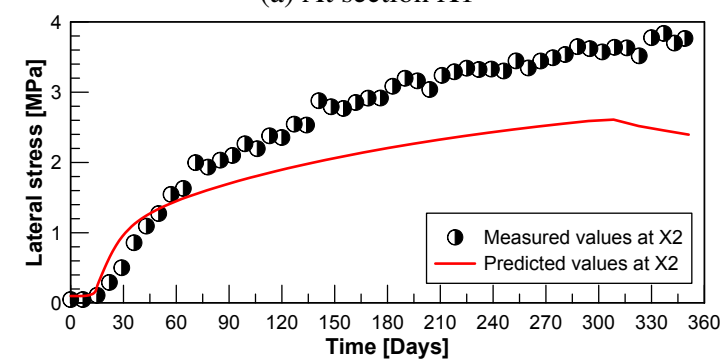

(b) At section $\mathrm{X} 2$

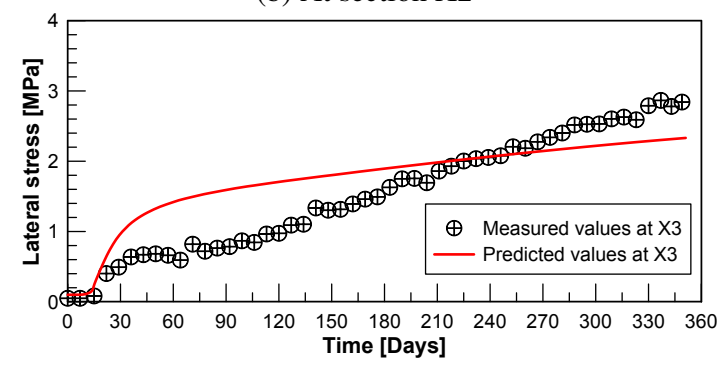

(c) At section X3

Figure 9. Measured and predicted lateral stress values

tions showed a good agreement with the measured data at section $\mathrm{X} 1$, however the predicted values disagree with the measured data at sections X2 and X3. In general, the swelling behaviour of compacted bentonite-sand mixture during the hydration from one end involves various complex processes, such as soil swelling, interaction between different soil layers and non-uniform changes in the sample condition during the progressive hydration process. Additionally, the presence of technical/constructional gaps and non-uniform soil stiffness along the height of soil sample during the heterogeneous hydration process are also responsible for a different axial and lateral swelling pressure dynamics.

\section{Conclusions}

A methodology for identifying and calibrating the model parameters for a fully coupled hydro-mechanical analysis is proposed based on the conventional laboratorybased experiments on elementary soil samples. The experimental results revealed the moisture migration along the height of unsaturated soil specimen under an applied hydraulic gradient. The double structure soil water retention model proposed by Dieudonne et al. [4] successfully captured the moisture migration process in the compacted soil specimen. The axial and lateral total stress measurements during the water infiltration highlighted the consequences of a heterogeneous moisture distribution in compacted bentonite-based materials. A comparative analysis of the measured and predicted total stress values along the height of soil specimen signifies the role of interfacial friction between the soil sample and cell-wall and anisotropic swelling behaviour, which provides the key inputs to improve the existing constitutive models for a coupled hydromechanical analysis.

\section{References}

[1] E.E. Alonso, A. Gens, A. Josa, Géotechnique. 40, 405 (1990)

[2] J. Vaunat, A. Gens, Engineering geology 81, 317 (2005)

[3] C. Gatabin, J. Talandier, F. Collin, R. Charlier, A.C. Dieudonné, Applied Clay Science 121, 57 (2016)

[4] A.C. Dieudonne, G. Della Vecchia, R. Charlier, Canadian Geotechnical Journal 54, 915 (2017)

[5] S. Wheeler, D. Gallipoli, M. Karstunen, International journal for numerical and analytical methods in Geomechanics 26, 1561 (2002)

[6] D. Gallipoli, F. D’Onza, S.J. Wheeler, Canadian Geotechnical Journal 47, 1175 (????)

[7] DIN18123, Soil, investigation and testing - determination of grain-size distribution (1996)

[8] A. Rawat, W. Baille, S. Tripathy, Engineering Geology 257, 105 (2019)

[9] A.J. García-Tornel, Ph.D. thesis, Universitat Politècnica de Catalunya (1988)

[10] J. Maswoswe, Ph.D. thesis, Imperial College London (University of London) (1985)

[11] S. Wheeler, V. Sivakumar, Géotechnique 45, 35 (1995)

[12] S.S. Agus, Ph.D. thesis, Bauhaus-University Weimar (2005)

[13] G. Della Vecchia, A.C. Dieudonné, C. Jommi, R. Charlier, International Journal for Numerical and Analytical Methods in Geomechanics 39, 702 (2015)

[14] J. Kozeny, Wien: Sitzungsbericht Akademie der Wissenschaften (1936)

[15] P. Carman, Trans. Inst. Chem. Eng. 16, 168 (1938)

[16] N.T. Long, Ph.D. thesis, Ruhr-Universität Bochum (2014)

[17] M.T. Van Genuchten, Soil science society of America journal 44, 892 (1980) 